\title{
Analyses of Incidents of Institutional Food Service Practice Management for One Year in the Kitchen of a General Hospital, Chubu Region, Japan
}

\author{
Satomi Maruyama ${ }^{1}$, Mitsuaki Ichie $^{2}$ and Tadahisa Tsuruta ${ }^{3}$ \\ 1. Department of Food and Nutritional Environment, Kinjo Gakuin University, Nagoya 4638521, Japan \\ 2. Nutrition Department, Nagoya Ekisaikai Hospital, Nagoya 4548502, Japan \\ 3. Quality and Patient Safety Department, Nagoya Ekisaikai Hospital, Nagoya 4548502, Japan
}

\begin{abstract}
This study aimed to assess the incidence of institutional food service practice management errors in the kitchen of a general hospital, Chubu region, Japan. Clarifying the cause of incidents of institutional food service operation can reduce institutional food service practice management errors. This is the first study to analyze incidents at a general hospital kitchen in Japan in English. Data were collected from incident reports over the course of one year, between October 1, 2011 and November 30, 2012. Forty two reports of incidents whose locations were the kitchen were analyzed, for example, incident dates, incident times, workloads, incident contents, incident causes, accident levels, and the presence or absence of negligence. The frequency of incidents for months, for each third of month, for day of week, for time of day, for workload levels of staff member, and for types of incidents were analyzed using chi-square test following Ryan multiple comparison. The incidents were more likely to occur at the start of the business year, during the 11:00 to 12:59 time blocks, and when staffs were busy. Breakdown of incident contents of “foreign contamination (hair)” was 10 reports (24\%). To prevent incidents, new staff should also be trained to acquire skills to avoid making errors during food preparation, ensuring that there is a clear route for communicating changes in the number of hospitalized patients, and building a system that allows for changes to be made to the number of meals to be served and the content of those meals in an accurate and prompt fashion. Furthermore, work uniform should be changed promptly as such contamination can reportedly be improved by having workers wear a work cap.
\end{abstract}

Key words: Incident, institutional food service, kitchen of a general hospital.

\section{Introduction}

In Japan, institutional food service is regulated by multiple laws, such as the Health Promotion Law, the Long-Term Care Insurance Act, and the Act on Social Welfare for the Elderly and the Child Welfare Act. As of March 2012 institutional food service was offered at a total of 86,661 institutions [1]. These institutions include schools, hospitals and nursing homes. The contents of institutional food service operations vary based not only on scale or the laws regulating them, but also by management organization.

In Japan, institutional food service operation management is categorized as a type of nutritional

Corresponding author: Satomi Maruyama, Ph.D., research field: clinical nutrition. E-mail: maruyama@kinjo-u.ac.jp. management, and hospital institutional food is therapeutic food provided to patients staying at the hospital. Because of this, risk management is supposed to be a priority issue in the management of institutional food service in hospitals, which achieve medical treatment safety.

Japanese hospital institutional food service operation management activities consist of institutional food planning, preparation, serving and evaluation. Within these hospital institutional food service operation management activities, the preparation and serving processes involve not only dietitians and registered dietitians, nutrition division specialists, but also a range of other professions, such as cooks and cooking staff [2]. Incidents in kitchens are directly tied to institutional food service operation 


\section{Analyses of Incidents of Institutional Food Service Practice Management for One Year in the Kitchen of a 197 General Hospital, Chubu Region, Japan}

management accidents [3]. Therefore, analysis of kitchen incidents is essential to reducing the number of institutional food service operation errors and improving the quality of medical treatment.

Reports of incidents by nutritional management divisions in Japan include the frequency and contents of incidents in one individual hospital $[4,5]$, the total number of monthly incidents and accidents reported in the "2012 Business Year Policy Issues-Report on the Nationwide Acute Care Hospital Nutrition Division Study and Hospital Ward Operation Study", a report issued by the Japan Dietetic Association [6]. Incidents have been reported to be linked to worker's fatigue [7], and the number of reports regarding incidents when serving meals has been reported [8]. However, there have been no reports of analyses of incidents in hospital kitchens. In this research we analyzed the incidents which occurred over the course of a year in the kitchen of a general hospital. This research clearly indicates the actual conditions of errors which occurred in a hospital kitchen, and is of value in institutional food service operation management.

\section{Methods}

This research consists of a cross-sectional study. In this research we conducted evaluations of reports created over the course of one year, between October 1, 2011 and November 30, 2012, of incidents at a general hospital in Japan's Chubu region. Incident reports from that one-year period were obtained from the Quality and Patient Safety Department after approval was given by the Ethical Review Board of Nagoya Ekisaikai Hospital. The general hospital is in the Chubu area of Japan, with 662 beds and 989 health professionals. The health professionals in the Dietary Department of the Hospital during the survey consisted of three registered dietitians, one cook, and five cooking staff directly managed by the hospital, and six registered dietitians, seven dietitians, five cooks, and 22 cooking staff under consignment contracts.

They staggered working hours to work, with two days off per week, as specified by law. Workers on the early shift were assigned to work at 7:30 or 12:00, so the early shift was divided into an early shift and a semi-early shift. Their working hours were as follows: five cooks worked the early shift (4:30 to 15:00), four registered dietitians and dietitians and one cooking staff member worked the early shift (5:00 to 15:00), one registered dietitian or dietitian worked the semi early shift (6:30 to 17:00), seven cooking staff worked the semi early shift (6:00 to 13:00), seven registered dietitians and dietitians worked the day shift (8:00 to 18:30), seven cooking staff worked the day shift (9:00 to 18:00), one registered dietitian or dietitian worked the late shift (10:00 to 20:00), and seven cooking staff worked the late shift (15:30 to 19:30). Four hundred meals were prepared for each meal time during the survey period, with a total meal service of 1,200 meals per day.

Incident reports consisted of the following items: Incident date, incident time, incident location, profession of reporter, workload, incident contents, incident cause, accident level, presence or absence of negligence, and future measures. Frequency of incidents, days of the week, months, workload levels of staff member, and types of incidents were collected from incident reports in the hospital. Workload levels of staff member showed four levels such as "extremely busy”, "busy”, "normal”, "somewhat low workload”, and "others". Types of incidents classified into contamination of hair, contamination of plastic, contamination of insects, serving prohibited foods, serving harder foods than those ordered, serving with wrong amount, serving with wrong ingredients, no serving at all, serving foods expired, serving food without filling out order and serving food obviously degraded. Frequency of incidents for months, for each third of month, for day of the week, for time of day, for workload levels of staff member, and for types of incidents were analyzed using chi-square test following Ryan multiple comparison by R version 2.10.1. Dietary department staff members were involved in kitchen 
work during their working hours. Incident reports were filled out by the staff member who discovered the incident. When several staff members were involved, the supervising staff member filled out the report. After filling out the report, the staff member added their speculations as to what caused the incident and submitted the completed incident report to the hospital's medical safety measures committee, which undertook efforts to improve such management errors. Incident contents, incident causes, and future measures were entered freely. One of three categories were selected for accident levels: "level 0: error which was not executed (detected in advance), or problem noted in medication or medical equipment, but with no effect on patient”; "level 1: no harm to patient (but unable to rule out some impact on patient)"; and "level 2: harm to patient". One of two categories was selected for the presence or absence of negligence: "negligence" and "no negligence". One of four categories was selected for the incident cause: "insufficient confirmation”, "judgment error", "insufficient observation" and "other".

The items from each of the collected incidents were coded. The data were input by the researchers using a defined format. The data were entered into Microsoft Excel.

Before the start of this study, ethical clearance was obtained from the Ethical Review Board of Nagoya Ekisaikai Hospital. This study was limited to the analysis of incidents in the kitchen. The names of health professionals and cooking staff were replaced with codes to avoid individual identifiers.

\section{Results}

During the period from October 1, 2011 to November 30, 2012, there were 42 reports of incidents whose locations were the kitchen. All reports were made by registered dietitians or dietitians.

Frequency of incidents for months, for each third of month, for day of the week showed no significant difference (Tables 1-3, by chi-square test). Whereas, frequency of incidents for time of day, for workload levels of staff member, and for types of incidents were significant at $P$-value less than 0.001 (Tables 4-6, by chi-square test). Frequency of incidents often occurred at 11:00 to 12:59 (Table 4, by Ryan multiple comparison). Little incidents occurred at lower level of workload of staff member (Table 5, by Ryan multiple comparison). Although there was no significance in frequency of incidents for types of incidents (Table 6, by Ryan multiple comparison), chi-square test showed significance in incidents for type of incidents $(P<$ 0.001). Contamination of hair showed the highest frequency in Table 6.

As shown in Table 1, the monthly breakdown of incidents is as follows: January-one incident (2\%); February-three incidents (7\%); March-two incidents (5\%); April—nine incidents (22\%); Maythree incidents (7\%); June-three incidents (7\%);

Table 1 The monthly breakdown of incidents.

\begin{tabular}{lll}
\hline Month & No. & Incident percentage (\%) \\
\hline January & 1 & 2 \\
February & 3 & 7 \\
March & 2 & 5 \\
April & 9 & 21 \\
May & 3 & 7 \\
June & 3 & 7 \\
July & 4 & 10 \\
August & 1 & 2 \\
September & 2 & 5 \\
October & 6 & 14 \\
November & 3 & 7 \\
December & 5 & 12 \\
Total & 42 & 100 \\
\hline
\end{tabular}

No significance in frequency of incidents for month by the chi-square test.

Table 2 The number of incidents which occurred in each third of each month.

\begin{tabular}{|c|c|c|}
\hline Each third of each month & No. & $\begin{array}{l}\text { Incident } \\
\text { percentage (\%) }\end{array}$ \\
\hline Start of the month (1st to the 10th) & 18 & 43 \\
\hline Middle of the month (11th to the 20th) & 13 & 31 \\
\hline $\begin{array}{l}\text { End of the month (21st to the end of } \\
\text { the month) }\end{array}$ & 11 & 26 \\
\hline Total & 42 & 100 \\
\hline
\end{tabular}




\section{Analyses of Incidents of Institutional Food Service Practice Management for One Year in the Kitchen of a 199 General Hospital, Chubu Region, Japan}

Table 3 The breakdown of incidents by the day of the week.

\begin{tabular}{lll}
\hline Day of the week & No. & Incident percentage (\%) \\
\hline Monday & 4 & 10 \\
Tuesday & 6 & 14 \\
Wednesday & 5 & 12 \\
Thursday & 9 & 21 \\
Friday & 9 & 21 \\
Saturday & 5 & 12 \\
Sunday & 4 & 10 \\
Total & 42 & 100
\end{tabular}

No significance in frequency of incidents for days of the week by the chi-square test.

Table 4 The breakdown of incident times.

\begin{tabular}{lll}
\hline Incident times & No. & Incident percentage (\%) \\
\hline $7: 00-8: 59$ & $12^{\mathrm{ab}}$ & 29 \\
9:00-10:59 & $0^{\mathrm{b}}$ & 0 \\
11:00-12:59 & $20^{\mathrm{cd}}$ & 48 \\
13:00-14:59 & $2^{\mathrm{a}}$ & 5 \\
15:00-16:59 & $1^{\mathrm{a}}$ & 2 \\
17:00-18:59 & $7^{\mathrm{a}}$ & 17 \\
19:00-20:59 & $0^{\mathrm{b}}$ & 0 \\
Total & 42 & 100 \\
\hline
\end{tabular}

$\overline{\mathrm{a}, \mathrm{b}, \mathrm{c}, \mathrm{d}}$ Significant difference by Ryan multiple comparisons $(P<$ $0.05)$.
Table 5 The breakdown of workloads.

\begin{tabular}{lll}
\hline Workloads & No. & Incident percentage (\%) \\
\hline Extremely busy & $7^{\mathrm{a}}$ & 17 \\
Busy & $15^{\mathrm{b}}$ & 36 \\
Normal & $17^{\mathrm{b}}$ & 40 \\
Somewhat low & $1^{\mathrm{ac}}$ & 2 \\
workload & $2^{\mathrm{ac}}$ & 5 \\
Other & 42 & 100 \\
Total & 42
\end{tabular}

a, b, c Significant difference by Ryan multiple comparisons $(P<$ $0.05)$.

July—four incidents (10\%); August—one incident (2\%); September-two incidents (5\%); October-six incidents (14\%); November - three incidents (7\%); and December-five incidents (12\%). The largest number of incidents occurred in April.

Table 2 shows the number of incidents which occurred in each third of each month. The 1st to the 10th of each month was defined as the start of the month, the 11th to the 20th as the middle of the month, and the 21st to the end of the month as the end of the month. 18 incidents occurred in the start of the month (43\%), 13 in the middle of the month (31\%), and 11 in

Table 6 The breakdown of incident contents.

\begin{tabular}{|c|c|c|c|c|c|}
\hline Incident contents & Detail & No. & Incident percentage (\%) & No. & Incident percentage (\%) \\
\hline \multirow[t]{4}{*}{ Foreign contamination } & & 16 & 38 & & \\
\hline & Hair & & & 10 & 24 \\
\hline & Plastic & & & 3 & 7 \\
\hline & Insects & & & 3 & 7 \\
\hline \multirow[t]{5}{*}{ Serving incorrect contents } & & 13 & 31 & & \\
\hline & Prohibited foods & & & 6 & 14 \\
\hline & Harder foods than those order & & & 3 & 7 \\
\hline & Wrong amount & & & 1 & 2 \\
\hline & Wrong ingredients & & & 3 & 7 \\
\hline \multirow[t]{6}{*}{ Other } & & 13 & 31 & & \\
\hline & Meals not being served & & & 9 & 21 \\
\hline & Expiration dates had passed & & & 1 & 2 \\
\hline & Food had mold & & & 1 & 2 \\
\hline & $\begin{array}{l}\text { Serving food without filling out } \\
\text { order }\end{array}$ & & & 1 & 2 \\
\hline & $\begin{array}{l}\text { Visible food product } \\
\text { degradation }\end{array}$ & & & 1 & 2 \\
\hline Total & & 42 & 100 & 42 & 100 \\
\hline
\end{tabular}

No significance by Ryan multiple comparisons. 
the end of the month (26\%).

Table 3 shows a breakdown of incidents by the day of the week on which they occurred. Four incidents occurred on Mondays (10\%), six incidents on Tuesdays (14\%), five incidents on Wednesdays (14\%), nine incidents on Thursdays (21\%), nine incidents on Fridays (21\%), five incidents on Saturdays (12\%). Table 4 shows a breakdown of incident times. Four incidents happened between 7:00 and 7:59 (9\%), eight incidents between 8:00 and 8:59 (19\%), 10 incidents between 11:00 and 11:59 (24\%), 10 incidents between 12:00 and 12:59 (24\%), two incidents between 13:00 and 13:59 (5\%), one incident between 16:00 and 16:59 (2\%), five incidents between 17:00 and 17:59 (12\%), and two incidents between 18:00 and 18:59 (5\%). The highest percentage of incidents occurred between 11:00 and 11:59, and between 12:00 and 12:59, at 10 incidents (24\%) for each block, followed by the 8:00 to 8:59 and the 17:00 to 17:59 time blocks.

Table 5 shows a breakdown of workloads. Seven incidents were occurred when the workload was "extremely busy" (17\%), 15 incidents when it was "busy" (36\%), 17 incidents when it was "normal" (40\%), one incident when there was a "somewhat low workload” (2\%), and two incidents for "other" (5\%).

Table 6 shows a breakdown of incident contents. These were divided into three categories: 16 incidents of "foreign contamination" (38\%), 13 incidents of "incorrect contents" (31\%), and 13 incidents of "other" (31\%). The breakdown of the foreign contaminants in the 16 incidents of foreign contamination was as follows: 10 incidents of hair (24\% of the total number of incidents) and three incidents of plastic and of insects each (7\% each). The breakdowns of the 13 incidents of incorrect contents were as follows: six incidents of serving prohibited foods (14\% of the total), three incidents of foods harder than the specified hardness and of foods with the wrong ingredients each (7\% each), and one incident of the wrong amount of food (2\%). The breakdown of the other 13 incidents were as follows: nine incidents of meals not being served ( $21 \%$ of the total), and one incident of serving food products whose expiration dates had passed or which had mold, serving food without filling out cautions, and visible food product degradation each ( $2 \%$ each).

There is no table showing a breakdown of the causes, but the breakdown was as follows: 40 incidents of "insufficient confirmation" (91\%), three incidents of "judgment error" (7\%), and one incident of "insufficient observation" (2\%). None of the incidents were a result of negligence. One incident had a level 0 accident level (2\%), and 41 incidents had a level one accident level (98\%). There was no actual harm to patients.

\section{Discussion}

This research analyzed 42 reports of kitchen incidents at a general hospital with 662 beds and 989 health professionals. 42 incidents occurred over the course of one year, for an average of 3.5 incidents per month. Previous research into the number of nutritional management related incidents in hospitals of a similar scale, covering 1,325 institutions, found that the average number of incidents per month was 8.63, and the median number was 2.00 [6], but these numbers are for all nutritional management related incidents, not limited to kitchen incidents. Therefore it is not possible to directly compare the number of incidents in this research to that in previous research, but we believe that 42 incidents per year in a hospital with over 600 beds represent a low number of incidents.

Looking at the number of incidents occurring per month, April accounted for the largest number of incidents, at $22 \%$, followed by October at $14 \%$ and December at $12 \%$. The new business year starts in Japan from April. There are many new staff members and assignment changes, so we believe that the largest number of incidents in April may be due to the fact that there are many people who are not yet used to their work, and communications may not be smooth. Next, comparing the periods within each month, 18 incidents 


\section{Analyses of Incidents of Institutional Food Service Practice Management for One Year in the Kitchen of a 201 General Hospital, Chubu Region, Japan}

(43\%) occurred within the first part of the month, from the 1st to the 10th. At the hospital studied, shifts were decided on a monthly basis, starting from the start of the month. New shifts meant new combinations of staff. It appears that the number of incidents may rise at the turning of the business year and the changing of shifts.

Looking at the number of incident reports by time block, the largest number of incidents occurred in the 11:00 to $11: 59$ and $12: 00$ to $12: 59$ time blocks, at 10 incidents each (24\%). 11:00 to $11: 59$ and $12: 00$ to 12:59 are the lunch preparation times. Because of new hospital admissions and discharges, there are many changes to the number and contents of meals served at lunch. Confirming the number and contents of meals is complex and cumbersome, which may account for the large number of incidents. The next highest number of incidents, after the $11: 00$ to $11: 59$ and $12: 00$ to $12: 59$ blocks, was the 8:00 to 8:59 block. The day shift workers who start their day at 9:00 have not yet arrived during the 8:00 to 8:59 time block, so the high number of incidents may be due to the low number of staff.

$53 \%$ of staff in incident reports indicated that they were extremely busy or busy. This shows that over half of the incidents occurred when staffs were busy. This indicates that incidents are more likely to occur when the workload is high. It may be possible to reduce the number of incidents by identifying and ameliorating the causes of this busyness.

With regards to incident contents, foreign contamination, incorrect contents and other contents accounted for over $30 \%$ each, indicating that care must be paid with all three types of incidents. Improvements in contamination by hair have reportedly been achieved through adjustments to work uniforms and revisions of incident reports [9]. The hospital that was evaluated in the present study may also be able to be improved using similar strategies. There were six incidents of serving prohibited foods, three incidents of serving the wrong food, such as serving foods containing allergens to allergic patients, three incidents of serving solid foods to patients requiring liquid food or soft semiliquid food. These errors could have had life or death implications and may develop into accidents.

Staff was identified "insufficient confirmation" as the cause of $91 \%$ of the incidents. This indicates that more thorough confirmation work, such as having confirmation performed by multiple staff members, performing confirmation out loud, etc., are necessary.

The Japan Council for Quality Health Care performs analyses of medical accidents. Medical institutions must implement accident prevention measures. Japanese hospital institutional food is therapeutic food served to hospital patients. Therefore, preventing institutional food service accidents in Japanese hospitals is essential to improving the quality of medical care they provide. This analysis of kitchen incident reports has found that a high number of incidents occur at the start of the business year, during the $11: 00$ to $11: 59$ and 12:00 to $12: 59$ time blocks, and when staffs feel that they are busy. Currently, 23\% of Japanese hospital institutional food service management division use directly operated food services, and $77 \%$ use contract food services. In the precedent study, the ratio of consignment contracts account of cooking (63\%), food preparation (66\%) and serving (67\%) were high [6]. In order to reduce the number of medical accidents, awareness needs to be raised, both among health professionals working directly for hospitals and among consignment contract health professionals, about when these incidents are likely to occur, and these staff must be educated to perform thorough confirmation work.

To our knowledge, this is the first study to analyze incidents at a general hospital in Japan.

There were several limitations to this study. As the authors investigated only one hospital, small numbers of incidents were analyzed. Another limitation was no classification in directly operated food services and contract food services. Further studies are required to indicate the actual conditions of errors which occurred in a hospital kitchen. 


\section{Conclusions}

Our analyses of incidents which occurred in the kitchen of a general hospital over the course of a year found that incidents were more likely to occur at the start of the business year, during the 11:00 to 11:59 and 12:00 to 12:59 time blocks, and when staffs were tired. Breakdown of incident contents were divided into three categories: "foreign contamination (i.e., hair, plastic and insects)", "incorrect contents", and "other". To prevent incidents at the start of the business year, not only should staff be given more intense training during March, but new staff should also be trained to acquire skills to avoid making errors during food preparation. The high frequency of incidents that occur at 11:00 and 12:00 could be improved by ensuring that there is a clear route for communicating changes in the number of hospitalized patients, and building a system that allows for changes to be made to the number of meals to be served and the content of those meals in an accurate and prompt fashion. The most common way that food was contaminated was with hair, so the work uniform should be changed promptly as such contamination can reportedly be improved by having workers wear a work cap that completely covers their head [9]. The limitation of this study is that the incident reports are analyzed in one year. In the future, we would like to collect incident reports from multiple years and present more detailed analytical results by investigating not only the months and days on which incidents occurred and the tiredness of staff, but also other attributes of staff such as age, sex, number of training sessions completed, years of work experience and professional background.

\section{References}

[1] Annual Health, Labour and Welfare Report 2012-2013 [Online], Oct. 24, 2013, p. 4, http://www.mhlw.go.jp/ toukei/saikin/hw/eisei_houkoku/12/dl/kekka2.pdf. (accessed June 18, 2014)

[2] T. Ishibashi, A study on the management, architectural planning and equipment of the kitchen on dietary department in acute hospitals, Bulletin of Hokusho University School of Human Service 15 (2012) 15-22. (in Japanese)

[3] F. Timinaga, Strategies for handling incidents and accidents related to patient meals in food service management, The Journal of Japan Society for Health Care Management 8 (2007) 191. (in Japanese)

[4] M. Takahashi, Reports and the inflection of incidents by nutritional management divisions, Journal of the Japan Dietetic Association 47 (2004) 292-294. (in Japanese)

[5] T. Tasaki, Risk management of nutritional management divisions-disaster and hygiene management, Journal of Clinical Nutrition 101-102 (2002) 165-171. ( in Japanese)

[6] Policy Problem 2012, General Survey of Nutritional Management Divisions in Acute Medical Institutes, Japan Dietetic Association Medical Division 2012 [Online], Nov. 1, 2013, p. 17, http://www.dietitian.or.jp/data/pdf/ h24-4.pdf. (accessed June 18, 2014)

[7] Y. Taguchi, S. Horie, T. Tsutsui, H. Igisu, Occupational safety and heal that small scale enterprises co-operating with a medical university, Journal of Occupational and Environmental Health 4-2 (2002) 197-210. (in Japanese)

[8] S. Yamashita, Crisis management system in a hospital to provide safe food, Journal of Clinical Nutrition 101-102 (2002) 177-181. ( in Japanese)

[9] S. Okabe, Trying out of analysis of frequent near-accidents to prevent contamination of hospital food with hair, Journal of the Japan Dietetic Association 54 (2011) 115-119. (in Japanese) 